
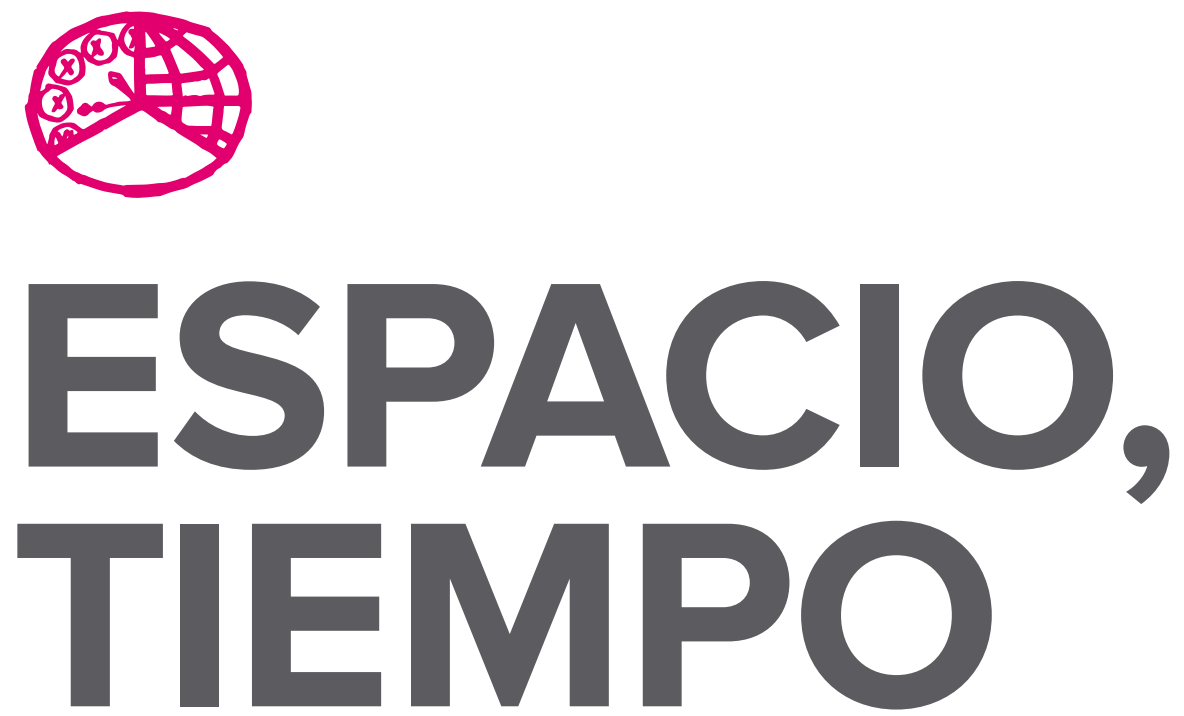

AÑO 2013

ISSN 1131-7698

E-ISSN 2340-1354
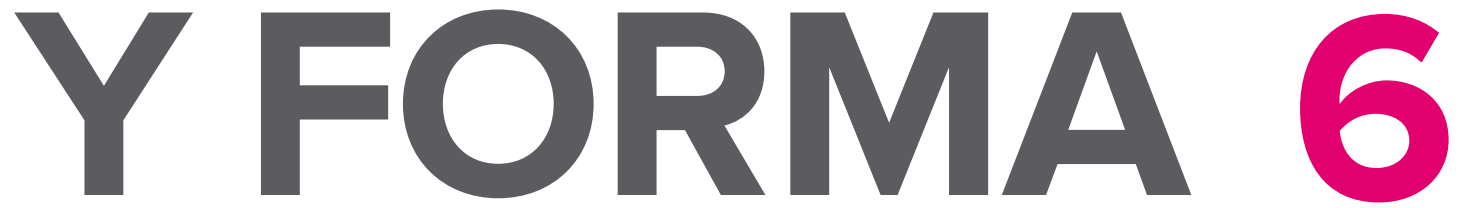

SERIE I PREHISTORIA Y ARQUEOLOGÍA

REVISTA DE LA FACULTAD DE GEOGRAFÍA E HISTORIA 

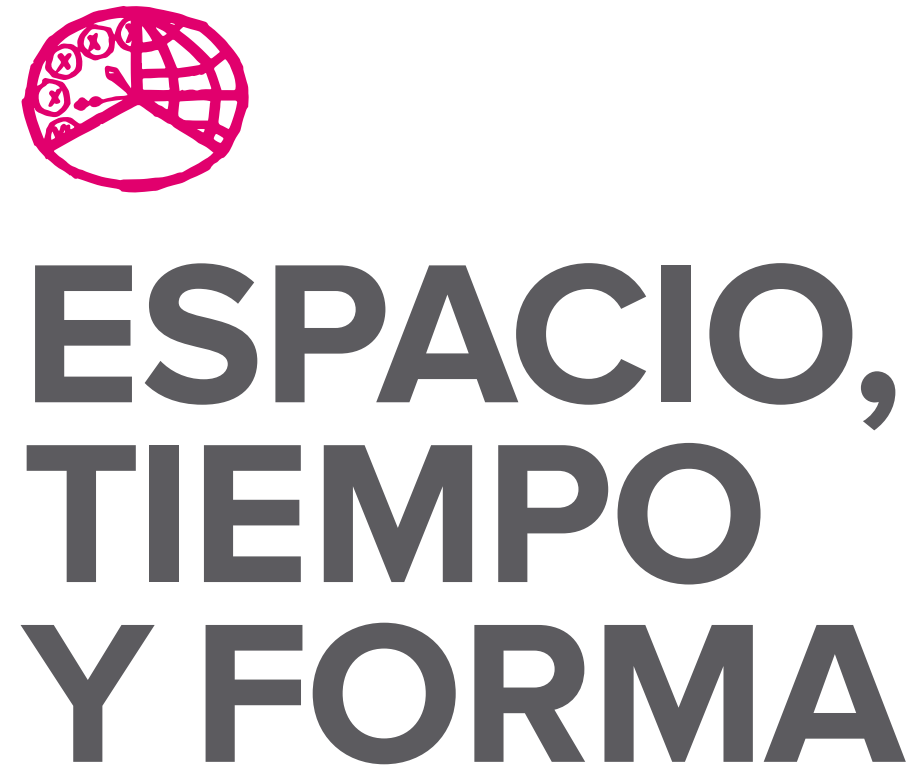

AÑO 2013

ISSN 1131-7698

E-ISSN 2340-1354

SERIE I PREHISTORIA Y ARQUEOLOGÍA

REVISTA DE LA FACULTAD DE GEOGRAFÍA E HISTORIA

DOI: http://dx.doi.org/10.5944/etfi.6.2013

\section{UกED}

UNIVERSIDAD NACIONAL DE EDUCACIÓN A DISTANCIA 
La revista Espacio, Tiempo y Forma (siglas recomendadas: ETF), de la Facultad de Geografía e Historia de la UNED, que inició su publicación el año 1988, está organizada de la siguiente forma:

$$
\begin{aligned}
& \text { SERIE I - Prehistoria y Arqueología } \\
& \text { SERIE II - Historia Antigua } \\
& \text { SERIE III - Historia Medieval } \\
& \text { SERIE IV - Historia Moderna } \\
& \text { SERIE V - Historia Contemporánea } \\
& \text { SERIE VI - Geografía } \\
& \text { SERIE VII - Historia del Arte }
\end{aligned}
$$

Excepcionalmente, algunos volúmenes del año 1988 atienden a la siguiente numeración:

$$
\begin{aligned}
& \mathrm{N}^{\circ} 1 \text { - Historia Contemporánea } \\
& \mathrm{N}^{\circ} 2 \text { - Historia del Arte } \\
& \mathrm{N}^{\circ} 3 \text { - Geografía } \\
& \mathrm{N} .^{\circ} 4 \text { - Historia Moderna }
\end{aligned}
$$

ETF no se solidariza necesariamente con las opiniones expresadas por los autores.

Espacio, Tiempo y Forma, Serie I está registrada e indexada, entre otros, por los siguientes Repertorios Bibliográficos y Bases de Datos: DICE, ISOC (CINDOC), RESH, IN-RECH, Dialnet, e-SPacio, UNED, CIRC, MIAR, FRANCIS, PIO, ULRICH'S, SUDOC, 2DB, ERIH (ESF).

\author{
UNIVERSIDAD NACIONAL DE EDUCACIÓN A DISTANCIA \\ Madrid, 2013 \\ SERIE I PREHISTORIA Y ARQUEOLOGÍA N. ${ }^{\circ}$ 6, 2013 \\ ISSN 1131-7698 · E-ISSN 2340-1354 \\ DEPÓSITO LEGAL \\ $M-21.037-1988$ \\ URL \\ ETF I PREHISTORIA Y ARQUEOLOGÍA · http://revistas.uned.es/index.php/ETFI/index \\ DISEÑO Y COMPOSICIÓN \\ Sandra Romano Martín · http://sandraromano.es \\ Ángela Gómez Perea · http://angelagomezperea.com \\ Impreso en España · Printed in Spain
}




\section{MONOGRÁFICO}

\section{ARTE RUPESTRE EN ÁFRICA, AMÉRICA, ASIA Y OCEANÍA}




\title{
DISTRIBUCIÓN DEL DISEÑO DE LAS CABEZAS MASCARIFORMES \\ EN LAS REPRESENTACIONES RUPESTRES DEL CENTRO OESTE ARGENTINO Y DEL NORTE CHICO CHILENO: ESTILO, IDENTIDAD Y PAISAJE
}

\author{
DISTRIBUTION OF MASK-LIKE FORMS DESIGN \\ IN ROCK ART OF CENTRE WEST \\ OF ARGENTINA AND SMALL NORTH \\ OF CHILE: STYLE, IDENTITY AND LANDSCAPE
}

Gabriela Inés Sabatini \& Vanina Victoria Terraza²

Recibido: 26/03/2014 - Aceptado: 24/01/2015

DOI: http://dx.doi.org/10.5944/etfi.6.2013.11168

\section{Resumen}

Se llevó a cabo un análisis sobre las representaciones rupestres del sitio Tunduqueral emplazado en el Valle de Uspallata, No de la Provincia de Mendoza, Argentina, ubicado en el periodo agroalfarero temprano-medio (siglos IV y x d.C.).

Basándonos en la relación entre arte y paisaje y en los conceptos teóricos sobre estilos tecnológicos buscamos comprender la materialidad de lo ritual a través del análisis comparativo de las cabezas mascariformes del Cerro Tunduqueral con las representaciones de sitios de San Juan: Los Colorados de Barreal, Quebrada de Aguas Blancas, Villa Dominguito en Sierra Pie de Palo y Quebrada La Chilca, y los hallados en el Norte Chico de Chile: Valle El Encanto (Ovalle), Llano-Pabellón de San Agustín (Valle del río Hurtado Superior) y Río Grande (Cuenca del río Limarí).

Consideramos que la recurrencia de los diseños a ambos lados de la cordillera de los Andes estaría mostrando ciertos vínculos (lazos comunitarios, de parentesco o vecindad) entre los grupos que ocuparon esta macrorregión, que persistieron y fueron recreados, pero que con el tiempo cobraron significaciones diferentes al ser incorporados a contextos políticos, económicos e ideológicos disímiles del original. Esto nos hablaría de una estrategia de comunicación visual entre puntos distantes a través de códigos simbólicos comunes.

1. FFyL-UNCuyo-SECTyP. Mendoza, Argentina.gabita_sabatini@hotmail.com.

2. FFyL-UNCuyo-SECTyP. Mendoza, Argentina.yepiana@hotmail.com. 
Palabras clave

Tunduqueral; paisaje; estilo tecnológico; cabezas mascariformes

\section{Abstract}

Rock art analysis had made of Tunduqueral site locate in Uspallata's valley, Nw of Mendoza, Argentina, during farmland-pottery early-late period $\left(4^{\text {th }}\right.$ and $\mathrm{IO}^{\text {th }} \mathrm{cen}$ turies AC).

Based on the relationship between art, landscape and theoretical concepts of technological styles we expect to understand the ritual material by the comparative analysis of mask-like forms in Tunduqueral' hill with the San Juan representations: Los Colorados de Barreal, Quebrada de Aguas Blancas, Villa Dominguito in Sierra Pie de Palo y Quebrada La Chilca, and Small North of Chile: Valle El Encanto (Ovalle), Llano-Pabellón de San Agustín (Valle del río Hurtado Superior) y Río Grande (Cuenca del río Limarí).

We consider the designs recurrence of both Andes places have been showing linkers (ties community, kinship and neighbourhood) between the groups whose took up the macroregion had persisted and had recreated, but over time they had different significations and incorporated in different politic, economic and ideological contexts. This similarity would speak about the strategy visual communication between fairways points by symbols codes community.

\section{Keywords}

Tunduqueral; landscape; technological style; mask-like forms 


\section{INTRODUCCIÓN}

Se escogió como estudio de caso el sitio Tunduqueral, ubicado en el valle de Uspallata, Noroeste de la provincia de Mendoza. Nuestro objetivo fue compilar el registro de las representaciones rupestres de un motivo en particular: las cabezas mascariformes y llevar a cabo un análisis comparativo con emplazamientos de sitios de San Juan: Los Colorados de Barreal, Quebrada de Aguas Blancas, Villa Dominguito en Sierra Pie de Palo y Quebrada La Chilca, y del Norte Chico de Chile: Valle El Encanto (Ovalle), Llano-Pabellón de San Agustín (Valle del río Hurtado Superior) y Río Grande (Cuenca del río Limarí).

Hemos analizado los atributos intrínsecos: diseños, composiciones, técnicas de producción y relaciones espaciales del arte rupestre, tomando el concepto de estilo entendido como una tecnología social que ha sido producida, compartida y repetida en el tiempo y espacio, siendo códigos que se transmiten entre generaciones y transfieren informaciones entre los segmentos sociales coetáneos y futuros (Aschero 2003). Se considera que existe un sistema de saber-poder transmitido y materializado por medio de imágenes que se expresa a través de los motivos escogidos, la técnica de producción, los soportes utilizados, la localización espacial y la articulación de los motivos al interior del panel (Troncoso, 200I: I). De este modo, podemos hablar de un estilo de arte rupestre que se repite en ambos lados de la Cordillera de los Andes, caracterizado por el motivo de las cabezas-tiara o mascariformes. Lo que nos interesa destacar es la similitud entre los diseños, los soportes gráficos y las técnicas de producción en diferentes espacios geográficos, así como la elección de determinadas modalidades espaciales para la configuración de las representaciones.

Afirmamos que el arte rupestre es parte de la cultura material, la cual se emplaza en el espacio a partir de una forma única y particular de concebir y experimentar al mismo por parte del grupo humano que la creó. Es decir que subyace a este modo de usar el espacio una forma de representación cultural que le otorga sentido (Criado 1999). El espacio es producto de formas de pensamiento particulares que lo estructuran y regulan el modo en que se elabora la relación sociedad-entorno (Criado 200o) y, al mismo tiempo, es resultado de las formas de habitar de las comunidades. Es decir que estas últimas constituyen y significan al paisaje; interpretan el espacio, a través de su pensamiento subjetivo, y establecen relaciones con el mismo. El espacio es, entonces, un lugar producto de un pensar/habitar-construir que materializa la acción social del pasado (Troncoso 2008).

Si comprendemos a las representaciones rupestres como parte de la materialidad, podemos decir que las mismas juegan un papel fundamental en la conformación de las identidades individuales y colectivas. Esta perspectiva deriva de la antropología de la tecnología (Lemonnier I977, I992) y de la idea de las representaciones sociales de los productores. La tecnología se hace visible en la materialidad y está integrada por habilidades, conocimientos, metas, necesidades, tradiciones, relaciones de poder, etc., además de la agencia social, el artificio y las relaciones sociales del artesano (Dobres I999). Así, la materialidad del arte rupestre permite la generación y el desarrollo de identidad, dado que los individuos que realizan actividades 
de producción de estos motivos sobre las rocas, al mismo tiempo crean y localizan identidades personales y grupales, dándose una afirmación y denominación sobre sí mismos que luego es leída por otros.

En este sentido, el arte rupestre es un medio para definir, negociar y comunicar una identidad social y, al mismo tiempo, un medio simbólico que les permite a sus productores una vinculación única y particular con su ambiente social y natural. En cualquiera de sus manifestaciones, espacios y épocas es un importante factor en la transformación de las relaciones sociales y la ideología. Al respecto, consideramos que el arte rupestre tiene un importante rol en la comunicación de la información como aquella que es producida, negociada, valorada, y significada por el grupo que la genera. La información que se transmite sirve para reforzar aquellas identidades individuales y grupales.

A partir de lo expuesto reflexionamos que el arte rupestre es una manifestación del lenguaje simbólico que refleja las relaciones humanas tanto con el mundo natural o físico como con el mundo sobrenatural o sagrado. No hay un solo factor de explicación, ambos mundos se penetran, se complementan y conforman una entidad compleja. El lenguaje simbólico, en términos de Fromm (I957), se define por la intensidad y la asociación, es decir por el sentimiento subjetivo que provoca un objeto o una situación destacable e interpretada como un símbolo importante y por la forma que contiene al símbolo - no su contenido. En relación al arte rupestre, defendemos que las semejanzas de los motivos (la forma o asociación, según Fromm i957) implicaría un mismo símbolo, el cual se repite en diferentes espacios. En otras palabras, observamos la intercomunicabilidad de una idea compartida a nivel macro-regional.

Siguiendo esta línea, planteamos que no debemos tener miedo de ver al arte rupestre como una alternativa de expresión de lo sagrado, de lo inexpresable a través de la razón. Si tomamos esta perspectiva, entenderemos nuestras representaciones en las rocas en el marco de una posible actividad sagrada, ritual o religiosa (Artigas 2008). Así, el estudio de los motivos mascariformes y su vinculación con el entorno, nos permite afirmar que las representaciones rupestres jugaron un papel fundamental en la conformación de espacios constitutivos de los procesos rituales.

\section{ARTE RUPESTRE EN LA SUBÁREA DEL CENTRO OESTE ARGENTINO}

La «Subárea Arqueológica Centro Oeste Argentino» (COA), adscripta dentro del «Área Andina Meridional» según la propuesta de Lagiglia (I968, I974), comprende actualmente el Oeste de la provincia de La Rioja, toda la provincia de San Juan, y la mitad norte de la de Mendoza, desde los $29^{\circ}$ hasta los $33^{\circ} \mathrm{S}$ aproximadamente. La Cordillera de los Andes la separa hacia el Oeste del centro-norte de Chile. Hacia el Este, un límite más o menos convencional estaría dado por el río Bermejo/Desaguadero (Abraham 200o). Más hacia el s y el sE se abre la «macro-área» de la Pampa y de la Patagonia, dominio de grupo de cazadores y recolectores hasta épocas tardías (FIG. I). 
Cuando se habla de la historia de las investigaciones sobre arte rupestre en la región se recuerda a Francisco P. Moreno quien dio a conocer el primer petroglifo de la región cuyana, ubicado en Canota (Mendoza) a fines del siglo XIX. Años más tarde Salvador Debenedetti director del Museo Etnográfico de Buenos Aires continuó con el interés del arte rupestre realizando expediciones al noroeste argentino y a la provincia de San Juan. Algunos geógrafos como F. Kuhn también realizaron aportes en ese sentido (Schobinger 2009).

Sin embargo, poco se sabía acerca del arte rupestre de esta región antes de I958. A parte de algunos sitios brevemente mencionados por algunos autores, solo Carlos Rusconi había realizado relevamientos en el noroeste de Mendoza y en el sudoeste de San Juan (Rus-

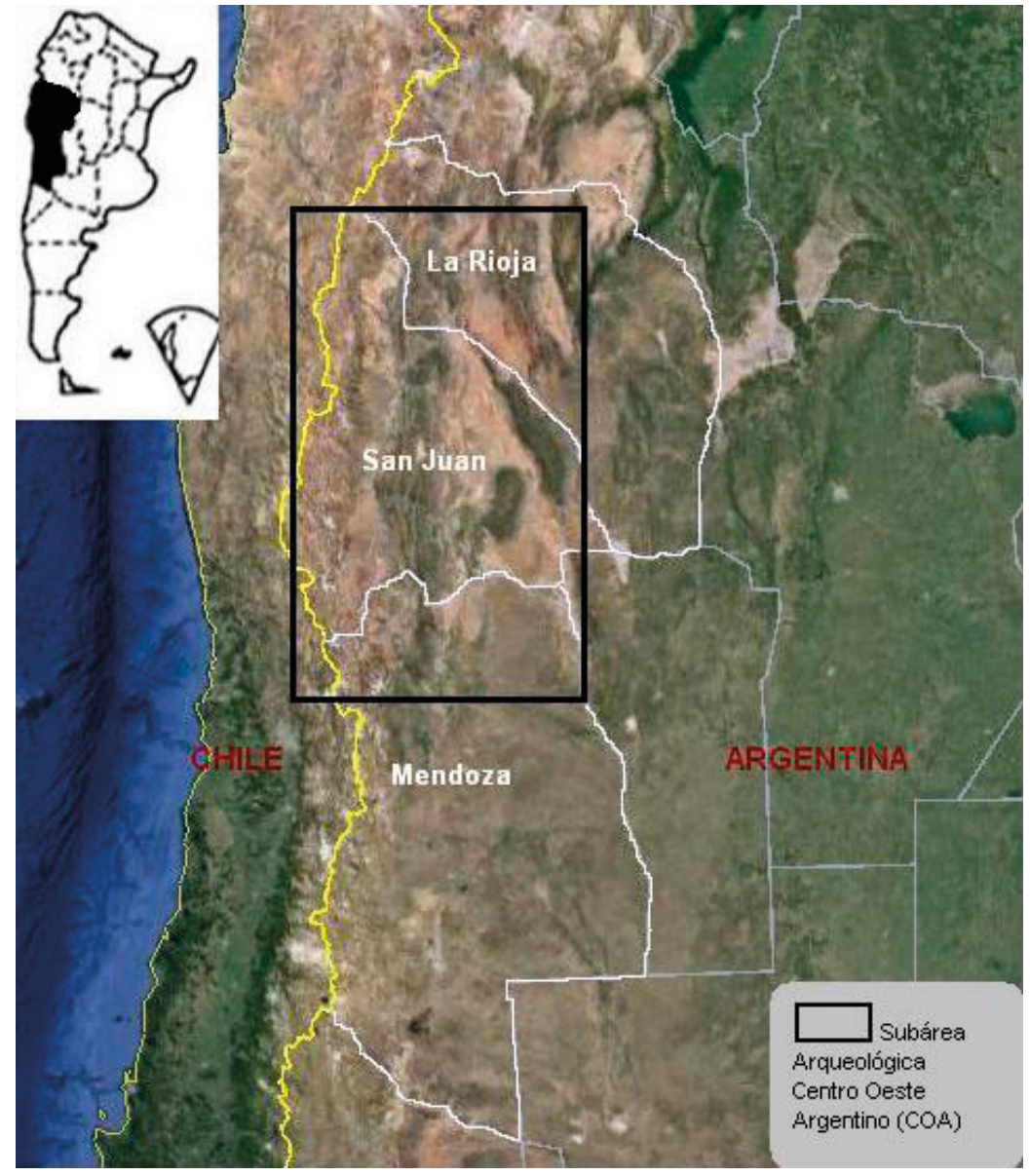

FIGURA 1. LOCALIZACIÓN DEL CENTRO OESTE ARGENTINO coni I962). Del total de sitios actualmente conocidos (en su mayoría con grabados) ocho fueron publicados por Rusconi (I962) uno por Kuhn (I9I4) y otro por Debenedetti (I9I7). Entre algunas de las locaciones que describe Rusconi (I962) con representaciones rupestres se destacan la zona arqueológica de Uspallata-Usina-Sur, el cerrillo al que el autor denomina «pucará» ubicado en el Potrero Los Álamos, la Quebrada de Santa Elena y el sitio El Peñón. Hacia fines de la década de los '5o Schobinger realiza y completa el relevamiento de algunos de estos sitios y proporciona nuevas evidencias sobre otros (Schobinger I962, I966, I968, I973, I975, I982, I985).

Actualmente se encuentran registrados unos Ioo sitios con representaciones rupestres (Schobinger 2009), en los cuales predominan los sitios con grabados; solo hay cuatro registrados con pinturas ubicados en el suroeste de San Juan. Del conjunto de grabados, hay alrededor de veinte locaciones de mayor importancia, destacables por la extensión o significación cualitativa (estética y cultural) de sus representaciones. Lo mismo puede decirse de uno o de dos de los sitios con pinturas. En general se hallan en el interior o al pie de las cadenas montañosas.

Los grabados se hallan a veces sobre paredones, más frecuentemente sobre rocas aisladas que suelen formar conjuntos de agrupaciones diseminadas en algunos 
conos de deyección o en el acceso o el interior de las quebradas. Estos lugares por lo general son inhóspitos, casi nunca asociados a sitios habitacionales, salvo los casos Los Colorados de Barreal y Villa Dominguito en Sierra Pie de Palo (San Juan) que se encuentran asociados a enterratorios (Schobinger y Gradin 1985). Las técnicas del grabado son muy uniformes consistiendo en el picado o martilleo con un percutor de piedra dura. La profundidad de los trazos difiere así como la apariencia y la conservación de acuerdo con la calidad de la roca. No parece haber una preferencia muy definida en cuanto a la orientación de los dibujos.

Como explican Schobinger \& Gradín (1985) no se han podido establecer diferencias estilísticas y cronológicas dentro del período de desarrollo del arte rupestre en la región. Existen motivos antropomorfos y zoomorfos siempre asociados a motivos geométricos rectilíneos y más frecuentemente curvilíneos. Predomina en el registro una tendencia irregular, en la que se destacan motivos simbólicos como las cabezas mascariformes y los antropomorfos enmascarados.

Los especialistas coinciden en ubicar al arte rupestre de la región dentro del periodo algroalfarero temprano-medio entre los siglos iv y $\mathrm{x}$ d.C. con posibles supervivencias posteriores.

\section{REPRESENTACIONES RUPESTRES EN EL VALLE DE USPALLATA, UN CASO DE ESTUDIO: CERRO TUNDUQUERAL}

El Valle de Uspallata se encuentra emplazado en el departamento de Las Heras, al No de Mendoza, con una altura que no supera los I.90o msnm (Shobinger 197I). Es una depresión longitudinal que separa a la Cordillera Frontal de la Precordillera con sentido Norte-Sur. Ha sido rellenado durante el Pleistoceno con grandes acumulaciones de origen aluvial y eólico (fundamentalmente del Holoceno). Desde la zona de Yalguaraz, el Valle de Uspallata, desciende suavemente hacia el norte desembocando en los valles Los Patos-Calingasta y hacia el sur limita con el Cordón del Tigre y la Precordillera, hasta encontrarse con los contrafuertes septentrionales del Cordón del Plata (Bárcena I977-I978).

El Valle de Uspallata representa una de las zonas arqueológicas más interesantes de la Provincia de Mendoza. Se le puede considerar como el más meridional de los valles longitudinales del noroeste argentino. Conocida es su significación en la época colonial como centro pastoril, agrícola y sobre todo centro minero, bajo la dirección de los Jesuitas hasta su expulsión en i767. Estos siguieron los pasos de los incas, que a fines del siglo xv extendieron su dominación hasta esta zona, y paralelamente hasta Chile central. Este dominio se evidencia en los tres tambos (albergues, sitios de habitación temporaria) que se hayan alineados a lo largo del camino del inca, a saber: Tambillos, Ranchillos y Tambillitos, a los que se agregan otros sitios ubicados más al norte, descubiertos y estudiados por Bárcena (I977).

Los trabajos de Rusconi y de Schobinger efectuados a partir de 1958 mostraron la presencia en esta zona de los grupos agroalfareros tempranos. Uno de los sitios más extenso es el denominado Uspallata-norte situado en el fondo del valle y 
formado por diversas concentraciones de material lítico (lascas, puntas de flechas) y fragmentos cerámicos, así como numerosas áreas de molienda.

Hacia I970 se halló un enterratorio sobre las barrancas del arroyo Uspallata conformado por un ajuar con una serie de puntas de flechas, adornos y vasijas de piedra, una gran pipa de piedra pulimentada con prolongación ofídica, y piezas de bronce, que fueron ubicadas aproximadamente en los siglos vill-IX A.D. (Rusconi I962, Schobinger I97I; I974-I976, Bárcena I974-I976). En el flanco de los cerrillos adyacentes, se halló una roca con grabados rupestres de motivos irregulares y curvilíneos y otra con motivos humanos esquematizados (Schobinger 197I). A estos descubrimientos se agregan los de la Quebrada de Santa Elena y los de El Peñón. En la quebrada mencionada se encontraron peñones con motivos curvilíneos y geométricos, mientras que en El Peñón se halló un grabado aislado de motivo curvilíneo que parecería ser un laberinto o máscara (Rusconi I962, Schobinger I97I).

Es preciso aclarar que los productores de estas representaciones rupestres habrían formado parte de sociedades consideradas «formativas», es decir sedentarias, con escasa diferenciación social y un componente productivo de intensidad media baja: agricultura a nivel doméstico complementada y optimizada con estrategias de caza, pesca y recolección (Cahiza 2003).

Estas poblaciones han dejado un importante legado: los grabados rupestres, que aparecen en varios sitios del valle y sus alrededores, entrando incluso en la zona cordillerana como un grupo situado a la salida de la quebrada del río Colorado sobre el alto río Mendoza. Lamentablemente, estos petroglifos fueron destruidos casi en su totalidad años atrás por quienes trabajaban en el trazado de la ruta internacional a Chile. El grupo principal de grabados rupestres que constituye el estudio de caso de este trabajo se halla en las rocas derrumbadas de unos cerrillos situados en el valle, sobre el extremo noreste del área de Uspallata norte.

El cerro Tunduqueral se encuentra a la vera de la ruta 52 , $7 \mathrm{~km}$ al norte de la villa de Uspallata (FIG. 2). Su nombre deriva de «tunduque» (Ctenomys mendocinus), roedor que durante el día suele esconderse bajo tierra formando galerías subterráneas. La estructura de las piedras es escamosa y algo

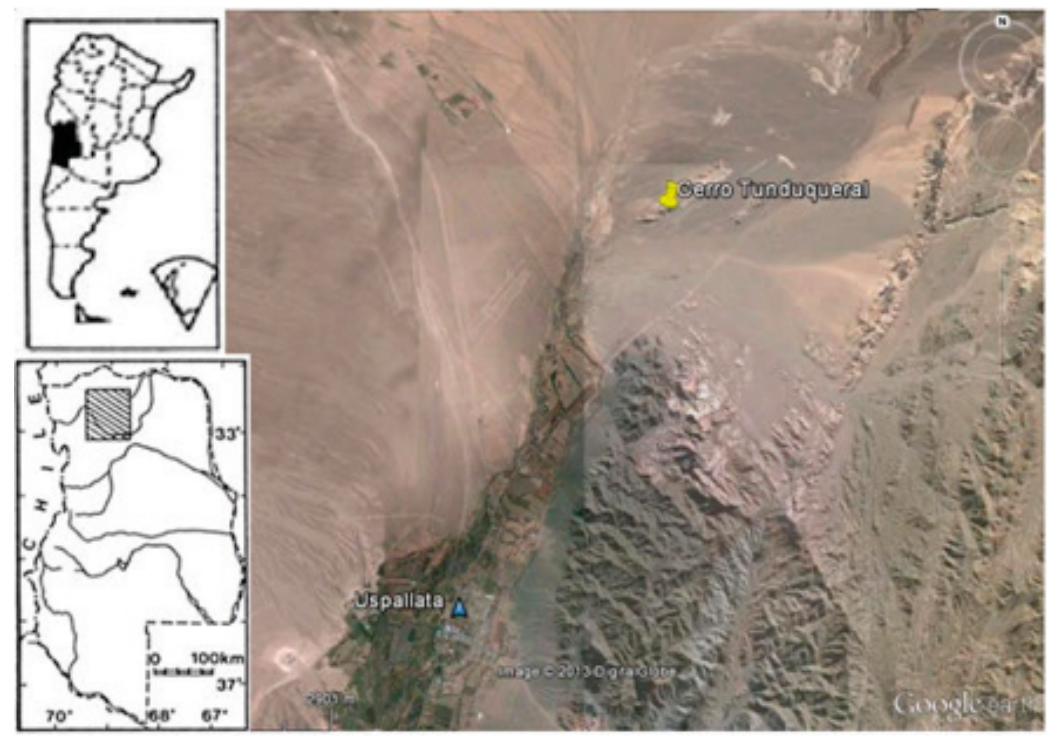

FIGURA 2. LOCALIZACIÓN DEL CERRO TUNDUQUERAL EN EL VALLE DE USPALLATA NO DE LA PROVINCIA DE MENDOZA, ARGENTINA. deleznable, probablemente de origen volcánico. Para el trazado de los grabados se han aprovechado las caras oscurecidas por las pátinas del desierto. Por lo general, en esta región, las medidas de cada unidad gráfica no 


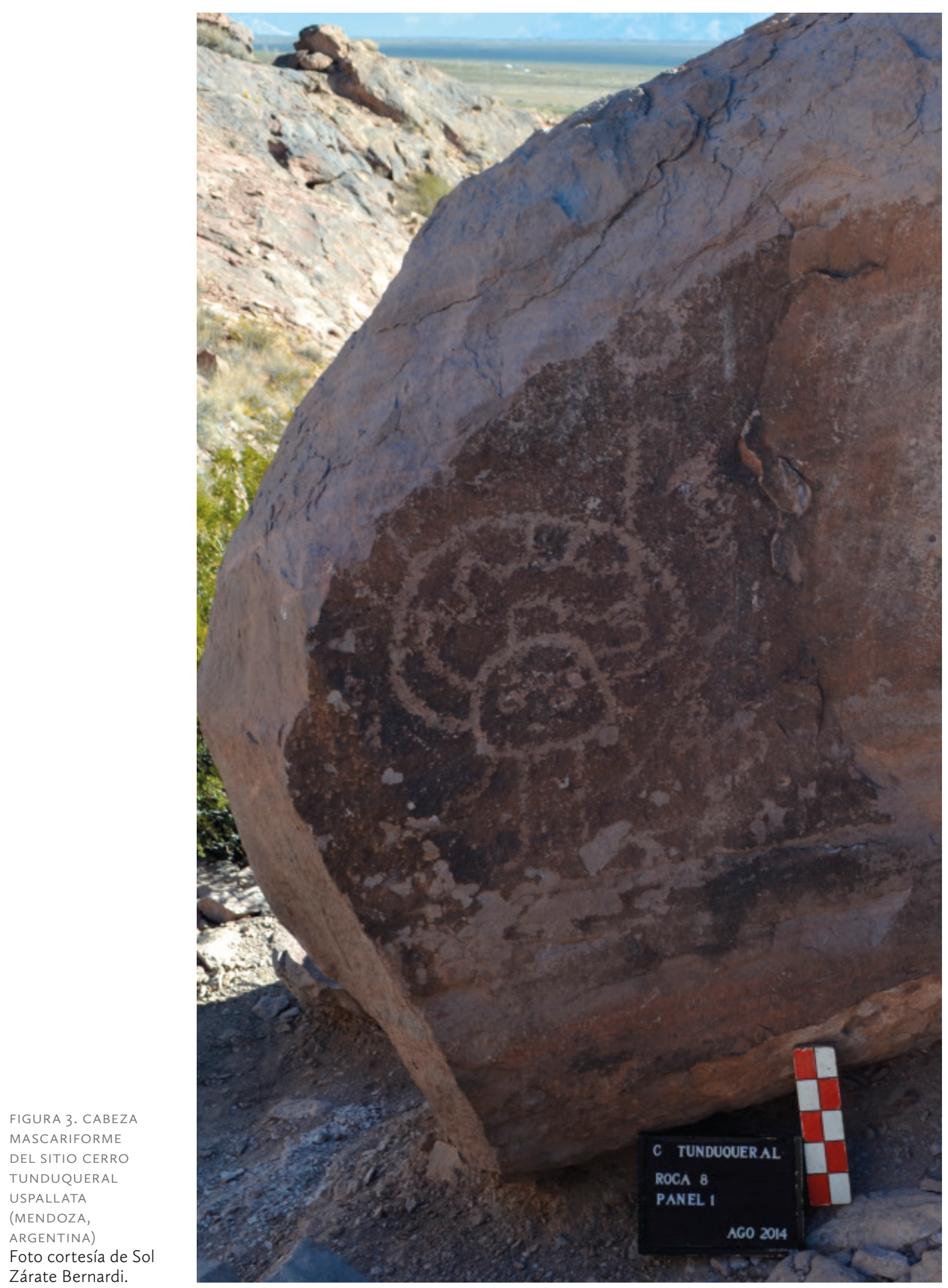

Zárate Bernardi. 
superan los $50 \mathrm{~cm}$. En los paneles se han identificado una serie muy variada de antropomorfos, dos de ellos de apariencia de avestruz, un «rostro» con grandes ojos y trazos que parten de la frente hacia el costado; hombrecillos simples, tridígitos ${ }^{3}$, líneas ondulantes y un motivo de desconocido simbolismo consistente en una línea horizontal de la que parten tres verticales hacia arriba, terminadas en sendas circunferencia con punto central. También se hallan dos pequeños cuadrúpedos esquematizados, probablemente camélidos. En otras de las paredes se observa un ave de rapiña (posible cóndor con las alas desplegadas), un antropomorfo con el sexo marcado, una «mujer con trenzas» (interpretado como un chamán guerrero) $\mathrm{y}$ un serpentiforme (Schobinger 2009).

Un caso especial es la figura de la cabeza mascariforme que mide $48 \mathrm{~cm}$ de altura y 40 de ancho. A la «cabeza» se le han agregado, en piqueteo más suave, piernas y brazos, e incluso, se insinúa la actitud de empuñar un objeto largo terminado en un pequeño círculo (maza o cetro). La cara presenta solo dos ojos circulares y una línea arqueada a modo de ceja. De los costados parte una aureola determinada por una doble línea parcialmente ondulante. Otro trazo parte del centro, y tras una doble curva continúa hacia arriba, para rematar en una circunferencia (FIG. 3).

Por último, otra figura peculiar es la de un hombre de $25 \mathrm{~cm}$ de altura que tira de un animal (probablemente un camélido). En su mano derecha parece sostener una vara; su vestimenta es sin duda un «uncu» (camiseta andina) constituyendo la única escena realista definida del cerro Tunduqueral (Schobinger 2009).

Las manifestaciones artísticas del sitio Tunduqueral han sido objeto de algunas interpretaciones, predominando aquellas que enfatizan el rol asociado con prácticas shamánicas. Una de ellas, quizás la más conocida, es la propuesta por Juan Schobinger. Este autor plantea la sacralidad del sitio y enfatiza el significado mágico-ritual de las representaciones. En sus propias palabras, afirma: «Todo indica que el lugar fue un sitio sagrado, en cuyas cercanías se realizaba algún tipo desconocido de ceremonias, de las que los petroglifos constituyen un único y pálido recuerdo» (Schobinger, 2009: 86). Esta afirmación la respalda con el análisis de los conjuntos de figuras existentes en las rocas, tomando como ejemplo, entre otros, el caso de la cabeza mascariforme, la cual, según su opinión «representa las fuerzas mágicas que para la percepción de los shamanes prehistóricos americanos irradia la cabeza humana» (Schobinger, 2009: 86).

Un interesante aporte dado por el mismo investigador es la comparación de la última figura mencionada con algunas representaciones ubicadas en la provincia de San Juan (al norte de la de Mendoza), así como también con motivos que aparecen en la provincia chilena de Coquimbo. El autor hace referencia a una recurrencia espacial y cronológica que caracterizaría a la cabeza mascariforme del Tunduqueral.

Siguiendo esta línea de interpretación, la artista visual Hart (2012) con colaboración del arqueólogo Horacio Chiavazza postula que estas figuras fueron confeccionadas en ceremonias, en las cuales se podría haber consumido sustancias

3. Schobinger (1982) denominó tridígitos a tres líneas unidas formando ángulos que podrían representar la pisada de ñandú. 
alucinógenas con el fin de alterar los sentidos y entrar en estado de trance. Estas manifestaciones antrópicas enfatizarían la cabeza humana como centro de poder y de conexión con otras dimensiones. Por otra parte, los autores explican la existencia de una jerarquización de los símbolos, teniendo en cuenta ciertos atributos como el tamaño de la figura y los elementos presentes o ausentes en sus cabezas. Así, los personajes de menor jerarquía son más pequeños y sin elementos en sus cabezas, por lo general están grabados de forma lineal y ocupan ubicaciones secundarias en el conjunto. Mientras que los de mayor jerarquía aparecen con ojos sobredimensionados, una gran cabeza, sosteniendo un posible bastón de mando o con extensiones en la cabeza tales como líneas que surgen como rayos o antenas. Estas extensiones estarían indicando un estado de conciencia modificado o trance, avalando la teoría shamánica aplicada al arte rupestre.

Las prácticas shamánicas y el consumo de alucinógenos han sido objeto de estudio en el Noroeste Argentino (Llamazares I999, 2000, 2003; Arado et al. 2000; Pérez Gollan \& Gordillo I993, Gudemos 20I2, entre otros) y en Chile (Núñez I967, Torres I983, I984, I986, Ballereau \& Niemeyer I999, Castelleti 2008).

\section{RELACIONES ENTRE LOS PETROGLIFOS DEL COA, CHILE Y NOROESTE ARGENTINO}

En la actualidad no se han realizado muchos estudios acerca del arte rupestre en el COA, a diferencia de lo ocurrido en el centro y norte semiáridos chilenos. Contamos con algunos trabajos con mapas de distribución (entre ellos, Niemeyer, I997; Mostny \& Niemeyer, 1983; Irribarren, I968; Niemeyer \& Montané, I968; Schobinger, 1982) y con nuevas perspectivas sobre el arte que ponen el acento en definiciones estilísticas y asociaciones con la Arqueología del Paisaje (Troncoso, I998, 200I, 2004; Troncoso et al., 2008, 20II, Cabello, 20II, Ballereau \& Niemeyer Fernández, I999; Niemeyer Fernández \& Ballereau, 2004).

A partir de la ubicación geográfica se pueden ver cuatro áreas de concentración de sitios en ambos lados de la Cordillera de Los Andes. El agrupamiento del arte rupestre se da en zonas ocupadas por culturas agroalfareras asimilables a un nivel calcolítico del siglo vill. Pero, algunas investigaciones han afirmado que la riqueza artística corresponde a los periodos Temprano y Medio más que al Tardío, y que, salvo muy pocos casos, la ejecución de grabados rupestres cae en desuso durante el periodo de dominación incaica (Schobinger \& Gradín I985, Schobinger 1982).

En primer lugar, existen semejanzas entre la zona septentrional del llamado Norte Chico chileno ubicado entre los ríos Huasco \& Elqui y el lado argentino con una importante concentración de sitios con grabados rupestres en el departamento de Iglesia y Jáchal, en el norte de la provincia de San Juan.

En segundo lugar, en el centro sur de la provincia de Coquimbo entre los ríos Hurtado, Limarí y Choapa (Chile) existen grabados de diversos tamaños y formas pero del lado argentino en la alta cuenca del río San Juan, Castaño, Calingasta y Los Patos la concentración del arte rupestre no es muy significativa. 
En tercer lugar, los grabados del Norte Chico chileno en el río Petorca y Aconcagua son similares a los detectados en la alta cuenca del río Mendoza y el noroeste y suroeste de San Juan. En general en el norte de Mendoza y San Juan el motivo que se repite es el de las «cabezas tiara» o «mascariformes» junto con figuras antropomoformas. En cambio, hacia el sur se observa una influencia del llamado estilo Aconcagua con figuras mascariformes simplificadas y los «signos escudos» (Niemeyer I968) cuyo prototipo se hallaría curiosamente en el noroeste de San Juan y no en Uspallata a pesar de su paralelismo geográfico.

En cuarto lugar, al sur de la provincia de Mendoza las representaciones chilenas son poco frecuentes, mientras que del lado argentino solo existen un grupo de pinturas rupestres situadas sobre el margen sur del río Atuel (Mendoza) pero se encuentran alejados del límite y no tienen una vinculación estilística con los chilenos (Schobinger I985) (FIG. 4).

En términos generales, hay una similitud técnica entre los tres primeros sectores mencionados, así como la ubicación del arte rupestre en zonas montañosas, valles, quebradas y portezuelo. Desde el punto de vista artístico Schobinger (I985) propone la existencia de un «aire de familia» común ya que la mayoría de las figuras son abstractas, geométricas curvilíneas y estilizadas o simbólicas. En cuanto a la relación entre Mendoza y San Juan, el autor afirma que los petroglifos del Valle de Uspallata son una prolongación del arte rupestre del suroeste de San Juan durante los siglos vili-X, disminuyendo o cesando los contactos entre ambas bandas cordilleranas.

\section{ANÁLISIS COMPARATIVO SOBRE EL DISEÑO DE LAS CABEZAS MASCARIFORMES}

Las locaciones a estudiar se encuentran enmarcadas en el Área Andina que comprende la mitad norte de Chile (Norte Grande, Norte Chico y Chile Central) y las regiones del Noroeste y Centro oeste de la Argentina. Este ámbito geográfico se estructura a partir de la gran Cordillera de Los Andes predominando en ambas franjas valles, quebradas, altiplanicies, mesetas, piedemontes andinos, llanuras aluvionales y serranías (Abraham 200o).

En la provincia de San Juan (Argentina) predominan las travesías, zonas llanas y sumamente áridas, en las que se levantan sierras aisladas, como las de Pie de Palo, Valle Fértil y de la Huerta. La temática del arte rupestre ha sido estudiada por Rusconi (I962), Kuhn, Debenedetti \& Gambier (I980) Schobinger \& Gradin (I985) y en años recientes por Varela \& Riveros (2004), Cahiza (2010-20II) y Bárcena (2013), entre otros.

En cuanto a la región del Norte Chico chileno predominan cordones montañosos transversales y valles fluviales, agrupando de norte a sur, las hoyas hidrográficas de los ríos Copiapó, Huasco, Elqui Limarí y Choapa (Ballereau \& Niemeyer 1999). Las manifestaciones artísticas localizadas en esta región han sido investigadas por Irribaren (I949, I953, I954, I955-56, I97I) Ampuero (I97I), Ampuero \& Rivera (I964, I969, I97I), Mostny \& Niemeyer (I983), Gordon (I985), Castillo (I985) Niemeyer (I994), Niemeyer \& Castillo (I996) y Ballerau \& Niemeyer (I999, 2004) entre otros. 


\subsection{SITIOS EN SAN JUAN}

\subsubsection{Quebrada de La Chilca}

El sitio las Chilcas Pintadas se encuentra al norte de Huaco en el departamento de Jáchal, al norte de la provincia de San Juan. Según Bárcena (2013) constituye una de las estaciones de arte rupestre más notoria del sector dominando el paso en las alturas inmediatas por su visibilidad plena de algunos motivos y el ocultamiento de otros. Los grabados y pinturas se encuentran en aleros, pasadizos y especie de túneles se destacan por su calidad formal y simbólica conformando un peculiar paisaje cultural.

El sitio presenta una compleja variedad de motivos (antropomorfos, zoomorfos, biomorfos y abstractos) destacándose la representación de las «cabezas tiara» o «cabezas aureoladas» de gran envergadura (un metro de ancho por sesenta centímetro de altura), motivo que ha sido picado sobre la pared frontal a $4 \mathrm{msnm}$ denotándose su visibilidad en el tránsito por la quebrada. Es un rostro con cejas, ojos, nariz, boca, enmarcado por un doble trazo oval dejando de lado al mentón donde se encuentra una figuración ovoide. Por encima de la cabeza se presenta un tocado cubriendo el sector superior y desbordando los laterales. Sumado a esto se muestran otras líneas transversales dentro del tocado. Otro de los motivos que llama la atención es una cara rectangular con una pirámide escalonada interna y atributo cefálico por encima dibujada en una piedra parada de gran visibilidad. Hasta el momento no se han llevado a cabo el análisis de los grabados y pinturas rupestres de La Chilca Pintada que permita relacionarlos con otro tipo de materialidad arqueológica del lugar, pero es probable que correspondan a los periodos temprano, de Integración y Desarrollos Regionales e Inka (Bárcena 2013).

\subsubsection{Quebrada de Aguas Blancas}

El sitio Quebrada de Aguas Blancas se encuentra en el departamento de Iglesia, noroeste de la provincia de San Juan. Se caracteriza por ser una locación con quebradas próximas poco profundas y muy irregulares en sus trazas; las imágenes se encuentran en los muros, pisos y en rocas sueltas. La técnica empleada ha sido la del bajorrelieve provocando así un punto ahuecado de pequeñas dimensiones. Uno de los principales motivos que aparece en el sitio es el de las figuraciones mascariformes, como la de un rostro con cejas, ojos, nariz, boca y mentón, con un tocado semicircular por encima de la cabeza que guarda en su interior decoración de apéndices lineales en forma vertical.

\subsubsection{Los Colorados de Barreal}

Barreal es una localidad perteneciente al departamento Calingasta, ubicada al extremo sur oeste de la provincia de San Juan. Al oeste de la localidad se ubican los 
Cerros Colorados, en donde se encuentran las representaciones rupestres, las cuales han sido asociadas a un antiguo enterratorio prehispánico. Se observa la presencia de una cabeza, con piernas, cuyo rostro presenta ojos y está coronado por una gran aureola, decorada internamente por líneas sinuosas.

\subsubsection{Villa Dominguito en la sierra de Pie de Palo}

Villa Dominguito es un distrito del departamento San Martín (centro sur de la provincia de San Juan) confinado en la base de la sierra de Pie de Palo. Se han registrado a lo largo de la sierra motivos rupestres antropomorfos, zoomorfos, geométricos, etc., de los cuales nos interesan las figuraciones humanas del tipo «enmascarado». Una de ellas, muestra a un antropomorfo con sus extremidades (asiendo algo con sus manos y acompañado por otro humanoide de menor tamaño), cuya cabeza presenta seis apéndices radiales.

\subsection{SITIOS EN CHILE}

\subsubsection{El Encanto}

Uno de los sitios de arte rupestre más estudiado en el Norte Semiárido chileno se encuentra en el Valle El Encanto. Ha sido el sitio-tipo para la caracterización del Estilo Limarí. El mismo se ubica en la margen sur del río Limarí, a unos io km al oeste de la actual ciudad de Ovalle, al interior de una quebrada regada por el estero Punitaqui. Se ha relevado un total de 69 bloques con arte rupestre, nueve de los cuales corresponden a pinturas. Las últimas investigaciones (Troncoso et al. 2008) han hecho hincapié en la redefinición del arte rupestre en El Encanto, a partir de la segregación de sus representaciones en tres conjuntos diferentes, asociados a los períodos Arcaico Tardío, Alfarero Temprano e Intermedio Tardío/Tardío, respectivamente. Para nuestro estudio nos hemos detenido sólo en las técnicas que se vinculan con diseños mascariformes.

Los autores destacan cuatro técnicas diferenciadas: I) pintura, 2) surco profundo $^{4}$, 3) surco superficial ${ }^{5}$ 4) combinación de pintura y grabado. Se pueden observar diseños mascariformes en las técnicas 2), 3) y 4).

En cuanto a la variabilidad iconográfica, en la técnica de grabado profundo se reconoce un total de 30 diseños, de los cuales el 43,4\% corresponden a I3 máscaras, mayormente cabezas-tiara, las que se caracterizan por ser representaciones de rostros de formas cuadrangulares o circulares, con una segmentación horizontal

4. La técnica de surco profundo consiste en la sustracción de una cantidad importante de superficie de la roca, de manera de dar forma a un surco grueso y profundo que construye la imagen.

5. Mientras que en la de surco superficial el proceso de elaboración implica la sustracción de una menor cantidad de superficie de la roca en comparación a la técnica anterior e involucra un piqueteado continuo en la piedra para delinear los diseños. 
en el sector medial del rostro, quedando en su parte superior ojos, nariz y ceja, que en ocasiones son del tipo ceja continua, mientras que en su parte inferior se dispone la boca. Sobre la cabeza, y comenzando en el tercio superior del rostro, se dispone un tocado de gran tamaño, caracterizado por su forma semicircular y por la presencia de decoración interna de tipo lineal formando diseños sinuosos, radiados o escalerados. Se incluyen en este conjunto dos representaciones de máscaras que presentan un rostro pequeño de forma circular con indicación de ojos, nariz y boca, pero con un tocado cefálico que no se constituye únicamente a partir de un contorno con decoración, sino que por dos apéndices lineales dobles laterales que angulan hacia arriba y un tercero que nace del sector medial del rostro hacia arriba con decoración interna de tipo línea.

Respecto a la técnica de surco superficial se registran un total de I73 diseños, de los cuales el 5,8\% (Io) corresponde a máscaras o representaciones de rostros con tocados cefálicos. Los mismos son diseños circulares en los que se indican los elementos internos de una cara y presentan apéndices lineales radiados en la zona superior del círculo, o bien, un tocado semicircular radiado, los que no alcanzan los atributos métricos de las cabezas-tiara, ni se asemejan en su composición interna.

En tanto que la técnica que combina grabado y pintura, se encuentra representada por sólo dos casos de máscaras. Una de estas dispone de una gran tiara con diseños escalerados en su interior y bajo ella se encuentra representado un rostro por medio de ceja, nariz, ojo y boca. A diferencia de todas las otras máscaras, ésta no tiene delineado el contorno del rostro y su cara es muy pequeña en relación al tamaño de la tiara.

Los autores hacen referencia a las superposiciones de unas figuras sobre otras y a partir del análisis de las mismas, proponen un registro estratigráfico en el arte rupestre que se inicia con las pinturas, continúa con las máscaras de surco profundo y acaba con los grabados de surco no profundo, donde priman figuras esquemáticas, así como antropomorfos con tocados radiales lineales.

De esta manera, se registra la existencia de diferentes ocupaciones en el arte rupestre del sitio, que determinarían la presencia de tres conjuntos estilísticos: I) Pinturas. Periodo Arcaico Tardío; 2) Cabezas tiara con técnica de surco profundo y círculos con apéndice. Período Alfarero Temprano; y 3) Diseños esquemáticos con técnica de surco superficial, figuras antropomorfas y zoomorfas. Algunas cabezas tiara, rostros y diseños diversos con técnica de surco profundo. Período Intermedio Tardío (I000-I400 d.C.) y Tardío (I400-I536/I54I d.C.) (Sánchez et al. I999, Pavlovic et al. 2004)

\subsubsection{El Llano de San Agustín}

Se ubica en la zona oriental del valle del río Hurtado, donde se han registrado 38 petroglifos, entre las cuales se hallan las cabezas mascariformes o máscaras con líneas verticales y espirales en el sector superior. Los autores destacan dos figuras significativas, una de ellas es un grabado realista con una estructura de simetría vertical, con una boca subrayada por un doble contorno. El otro grabado presenta 


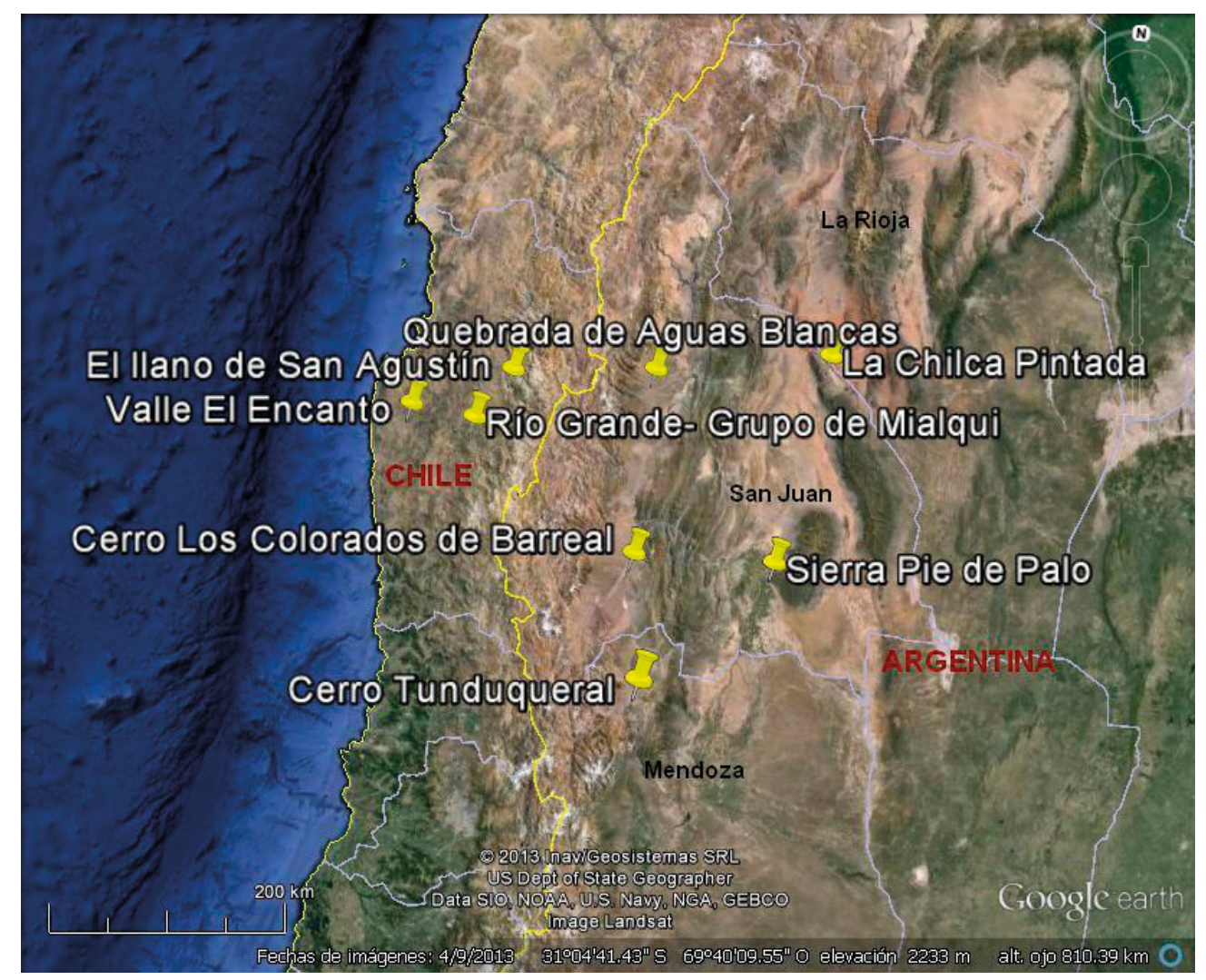

FIGURA 4. LOCALIZACIÓN DE LOS SITIOS CON REPRESENTACIONES RUPESTRES NOMBRADOS EN EL TEXTO

«atributos cefálicos con rayos divergentes superiores» (Ballereau \& Niemeyer 1999), boca circular y ornamentos laterales cuadrados, estructura reticulada rodeada por un ornamento que lo envuelve totalmente, rectángulo dividido irregularmente por segmentos horizontales y líneas en abanico. Según Ballereau \& Niemeyer (I999) estas representaciones han sido grabadas con un alto grado de estilización y se las ha emparentado con los diseños del Valle El Encanto.

\subsubsection{Río Grande}

En este afluente del Río Limarí, las investigaciones más próximas en el tiempo han detectado la presencia de numerosos grabados (342) que fueron hechos según la técnica del picoteado directo. Se registran varias estaciones de arte rupestre, de las cuales hemos tomado el denominado grupo de Mialqui (Mialqui, Mialqui Alto, Tucúquere y La Viñita) que presenta el diseño mascariforme en cuestión. Hemos tomado sólo dos mascariformes, a modo de síntesis. El primero es la representación de una cara humana circular, identificada como tal por dos ojos vaciados, cada uno circunvalado por un círculo. Tiene un diámetro medio de $0,39 \mathrm{~m}$. Dos líneas onduladas representan respectivamente la nariz y las cejas. La boca no parece marcada. El resto del rostro está ocupado por un conjunto de líneas desordenadas. Se 
observa, arriba de la cabeza, un pequeño rectángulo con cinco compartimientos. El segundo tiene un pequeño tamaño $(\mathrm{I} 8,5 \mathrm{~cm} \times \mathrm{I} 5 \mathrm{~cm})$ y una estructura poco evolucionada: rostro compuesto de dos ojos y una amplia boca, con adorno cefálico voluminoso que contiene una línea irregular.

TABLA 1. CABEZAS- TIARA O CABEZAS MASCARIFORMES

Diseño de las cabezas mascariformes en los sitios mencionados en el texto.

REGión/SITIO
Cerro Tunduqueral
(Mendoza)
Modalidades espaciales:
Cerro a 2.000 mts
sobre el nivel del mar.
Buena visibilidad, al
aire libre. Ausencia de
recintos habitacionales
adyacentes.

adyacentes.

\section{Sitio las Chilcas}

Pintadas (San Juan).

Buena visibilidad.

\section{ASIGNACIÓN TEMPORAL TÉCNICA}

DISEÑOS

Periodo algroalfarero temprano-medio entre los siglos IV y $\mathrm{x}$ d.C.
Piqueteado directo sobre pátina de desierto.

Cabezas piqueteadas suaves, piernas y brazos, empuñan un objeto largo terminado en un pequeño círculo. La cara presenta solo dos ojos circulares y una línea arqueada a modo de ceja. De los costados parte una aureola determinada por una doble línea parcialmente ondulante.
Periodo Temprano, de Integración y Desarrollos Regionales e Inka.
Picado sobre pared frontal.

Rostro con cejas, ojos, nariz, boca, enmarcado por un doble trazo oval dejando de lado al mentón con figuración ovoide. En la parte superior se encuentra un tocado. Además, se halló una cara rectangular con una pirámide escalonada interna y atributo cefálico.

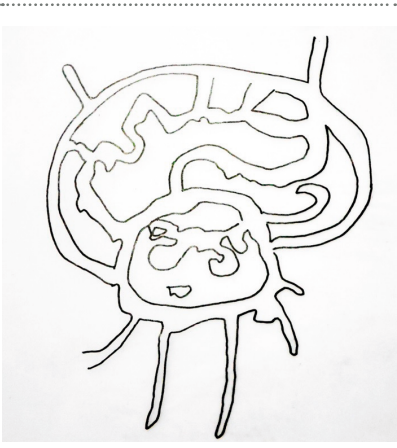

\section{Sitio Quebrada de Aguas Periodo algroalfarero Blancas (San Juan). Buena visibilidad.}

\section{Bajorrelieve.}

Rostro con cejas, ojos, nariz, boca y mentón, con un tocado semicircular por encima de la cabeza que guarda en su interior decoración de apéndices lineales en forma vertical.

\section{Sitio Los Colorados}

(San Juan).

Buena visibilidad,

al aire libre.

Asociado a enterratorio.
Periodo algroalfarero temprano-medio entre los siglos IV y $\mathrm{x}$ d.C.
Cabeza, con piernas, cuyo rostro presenta ojos y está coronado por una gran aureola, decorada internamente por líneas sinuosas.
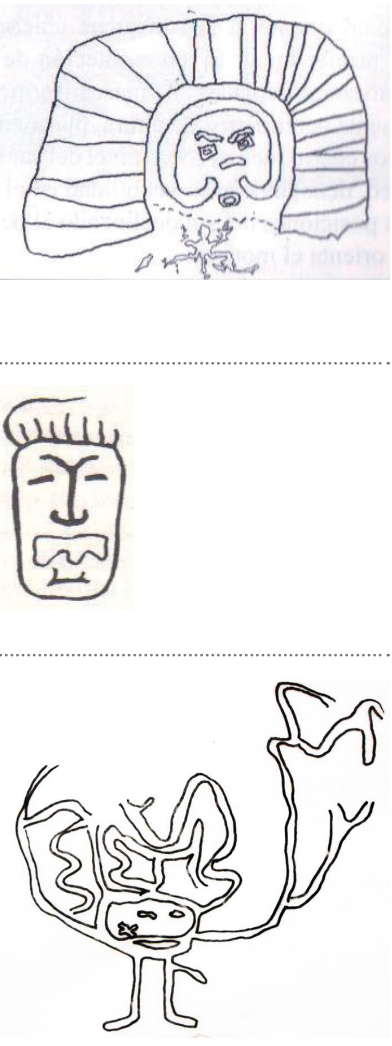

\begin{tabular}{|c|c|c|}
\hline $\begin{array}{l}\text { Sitio Sierra Pie de } \\
\text { Palo (San Juan). } \\
\text { Buena visibilidad, } \\
\text { al aire libre. } \\
\text { Asociado a enterratorio. }\end{array}$ & $\begin{array}{l}\text { Periodo algroalfarero } \\
\text { temprano-medio entre } \\
\text { los siglos IV y } \mathrm{x} \text { d.C. }\end{array}$ & $\begin{array}{l}\text { Antropomorfo con sus extremidades } \\
\text { (asiendo algo con sus manos y } \\
\text { acompañado por otro humanoide } \\
\text { de menor tamaño), cuya cabeza } \\
\text { presenta seis apéndices radiales. }\end{array}$ \\
\hline
\end{tabular}


REGIÓN/SITIO

Valle El Encanto (Chile).

Modalidades espaciales:

Valle, interior de

una quebrada.

Buena visibilidad

de los motivos.

Al aire libre.

\section{Período Alfarero \\ Temprano}

\section{Surco profundo.}

Rostros de formas circulares con una segmentación horizontal en el sector medial del rostro. parte superior: ojos, nariz y ceja; parte inferior: boca. Sobre la cabeza se dispone un tocado semicircular con decoración interna.
DISEÑOS

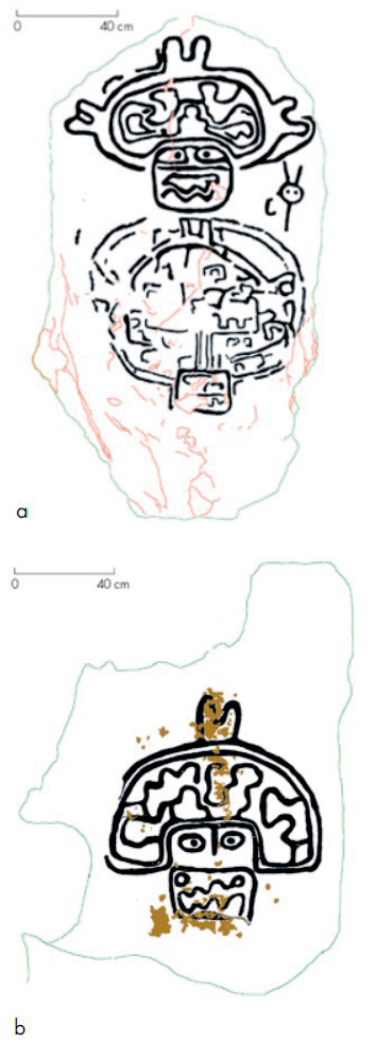

Surco superficial.
Diseños circulares en los que se indican los elementos internos de una cara y presentan apéndices lineales radiados en la zona superior con tocado semicircular radiado.

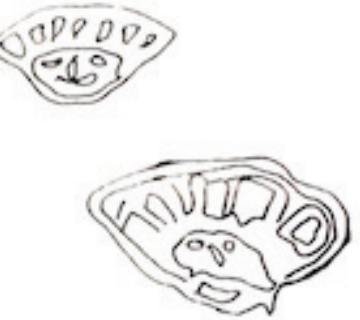

Combinación de grabado y pintura. Gran tiara con diseños escalerados en su interior y bajo ella se encuentra representado un rostro por medio de ceja, nariz, ojo y boca.

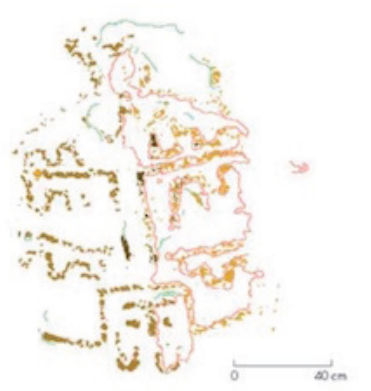




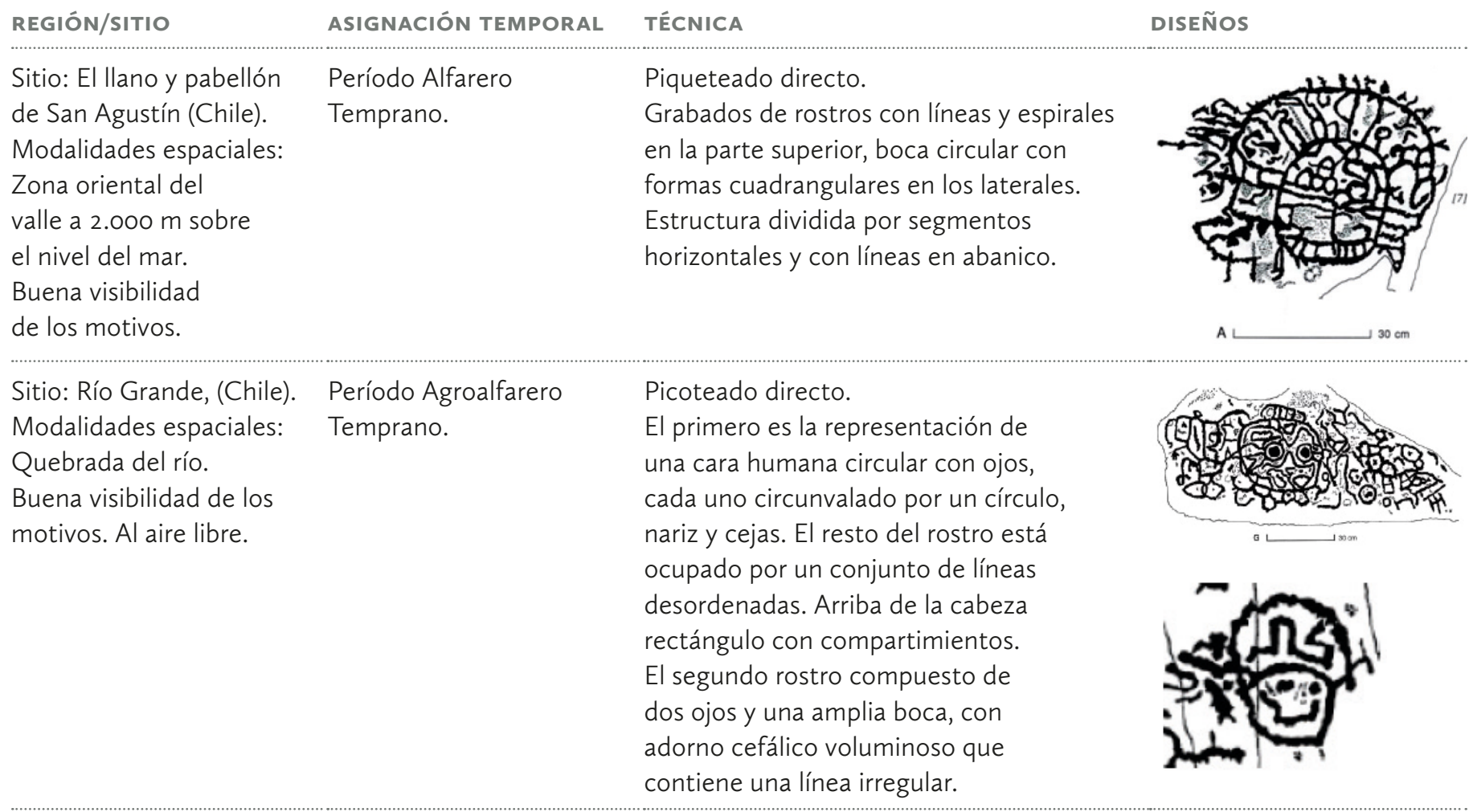

\section{DISCUSIÓN Y CONSIDERACIONES FINALES}

A partir de la comparación realizada (TABLA I) podemos llegar a algunas reflexiones. En primer lugar, los conjuntos rupestres se sitúan en zonas montañosas, específicamente en cerros, valles y quebradas. En todos los sitios analizados las representaciones presentan una visibilidad media-alta ya que se encuentran al aire libre y emplazadas en un lugar específico que les permite dominar el entorno natural y ser mensajes ampliamente accesibles no solo para el «nosotros» que se apropiaban regularmente del paisaje sino para «otros» que pudieron circular por el mismo e intentar acceder a sus recursos. De este modo, paisaje y arte son modelos de una realidad externa que sirven para ordenarla y darle sentido. La relación entre ambos es más estrecha pues las representaciones son un conjunto activo en la construcción de dicho paisaje y establece una de las formas posibles de apropiación del espacio. Es por esto que los emplazamientos seleccionados suelen asociarse a rasgos geográficos específicos ya mencionados jugando un rol central en la idea de territorialidad, considerada esta como un sistema de control sobre un área geográfica, no sólo entendida como una forma de promover ideas de posesión y demarcación del entorno sino también como ambientes construidos que transmiten mensajes acerca del orden social, las pautas de comportamiento y sobre una dimensión constitutiva de la identidad (Aschero 2007). Además, debemos tener en cuenta que los 
cerros, quebradas y valles serranos son protagonistas indiscutidos del paisaje andino influyendo en la cosmovisión de los grupos que los habitaron siendo estos puntos sagrados en el espacio con cualidades que trascienden en el tiempo.

En segundo lugar, estas representaciones forman parte de un mismo estilo al compartir el diseño, el modo de ser ejecutado, el soporte utilizado, etc.: las cabezas mascariformes o cabezas tiara, las cuales se presentan con rostros de formas cuadrangulares o circulares y en algunas se identifican ojos, nariz y ceja. Es llamativo el diseño circular o semicircular sobre la cabeza con la presencia de decoración interna de tipo lineal formando diseños sinuosos, radiados o escalerados. En general, los autores llaman a estos abanicos decorados «tocados u ornamentos» realizados en las zonas superiores y laterales de las cabezas. En cuanto a la técnica de producción se empleó el grabado o piqueteado sobre rocas volcánicas o graníticas.

Creemos que los diseños repetidos a ambos lados de la cordillera de los Andes estarían mostrando ciertos vínculos entre los grupos que ocuparon esta macrorregión, los cuales eligieron elementos comunes a partir de una amplia circulación expresando lazos comunitarios, de parentesco o vecindad que persistieron y fueron recreados, pero que con el tiempo cobraron significaciones diferentes al ser incorporados a contextos políticos, económicos e ideológicos disímiles del original. Esta recurrencia en los diseños nos hablaría entonces de una estrategia de comunicación visual entre puntos distantes a través de códigos simbólicos comunes.

Probablemente estos pueblos llevaron a cabo similares prácticas sociales, como pueden ser ceremonias, rituales, etc. que se plasmaron en la materialidad específica de las rocas. Así, la significación de estos lugares se halla relacionada con un sistema de creencias, de saberes, de comportamientos y de símbolos. Hemos dicho que en el caso del arte rupestre los símbolos toman forma de imagen. Estas imágenes podrían guardar relación con el mundo ritual y sobrenatural. Es probable que ciertas modalidades espaciales en las cuales las representaciones se hallan separadas de los lugares de reproducción de las estructuras sociales y de las actividades domésticas-residenciales, ubicándose en sitios elevados, con un acceso socialmente restringido, expresen formas rituales (Quesada et al. 20II).

La ritualidad es parte de la dinámica social y su dimensión simbólica se vuelve imprescindible para que la cultura tenga coherencia y significado, colaborando en la construcción de las identidades individuales y grupales. El rito permite una conexión simbólica entre el mundo cotidiano y el mundo sagrado, invocando, objetivando, transformando y perpetuando los valores culturales. Los ritos iniciáticos o shamánicos están asociados, más que a una forma exterior de la cultura o de economía, a un tipo de mentalidad (Schobinger 1997). Esta expresión busca entrar en contacto íntimo con el mundo natural y sus fuerzas sobrenaturales o divinas. En el caso del arte rupestre se ha visto, a modo de interpretación, cómo las manifestaciones artísticas reflejan prácticas iniciáticas, en las que las alucinaciones (o estados alterados de consciencia) tienen un rol central.

Asimismo se desea reafirmar la concepción del arte como un mensaje a descifrar, un medio de expresión del hombre que refleja sus expresiones creativas, su ideología, la organización de los grupos y su ordenación en el territorio, sus actividades económico-sociales, sus creencias y prácticas religiosas, hasta su visión del mundo y de la vida. 
Por otra parte destacamos que el Cerro Tunduqueral no presenta una asociación espacial con áreas residenciales propias de los grupos agroalfareros que permanecieron en el valle de Uspallata entre los siglos vi y Ix d.C. Es decir que, para este caso, el arte rupestre se encuentra fuera del sector doméstico y en vinculación con la actividad ritual. Esta hipótesis se reafirmaría con el estudio del diseño de las mascariformes confirmando las interpretaciones ya mencionadas.

Las analogías morfológicas y de manufacturación de las producciones rupestres de esta Subárea con las representaciones de Chile son evidentes. Un claro ejemplo es el de las cabezas mascariformes que se hallan en la iv Región de Chile (Norte Chico), asignadas a la cultura agro-alfarera El Molle entre los 200 y 300 años AP (Schobinger I982), y sus análogas en San Juan (Argentina) en los siglos iv y v, y en el norte de Mendoza en los siglos vil y vill (Schobinger I982). Esto parece marcar una tendencia temporal que podría sostener la proposición del origen trasandino del complejo de motivos mascariformes y su posterior desarrollo en el coA.

En este sentido creemos que estos diseños comparten semejanzas formales estilísticas, ubicándose en soportes distribuidos en un espacio o paisaje determinado y conformando de forma visual un conjunto que está relacionado conceptualmente. La regularidad de los mismos estaría dada por la pertenencia y la participación en un lenguaje simbólico común, establecido por tradición en determinados grupos humanos y adoptado por otros, quienes lo resignifican.

Estas líneas de investigación necesitan ser examinadas con mayor detenimiento y a la luz de nuevas evidencias, para lograr conocimientos más acabados sobre las relaciones espaciales y estilísticas que existen entre los sitios con representaciones rupestres en el COA y el Norte Chico y semiárido chileno. 


\section{BIBLIOGRAFÍA}

Abraham, E.M. (ed.) 2000: «Geomorfología de la provincia de Mendoza». Recursos y problemas ambientales de zona árida. Primera parte: provincias de Mendoza, San Juan y La Rioja, Caracterización ambiental. IDızA. Mendoza I: 29-48.

Ampuero, G. I97I: «Nuevos resultados de la arqueología del Norte Chico». Actas del vi Congreso Nacional de Arqueología Chilena. Sociedad Chilena de Arqueología. Universidad de Chile. Santiago: 3II-338.

Ampuero, G. \& Rivera, M. I964: «Excavaciones en la quebrada El Encanto, Departamento de Ovalle (informe preliminar)». Actas del 111 Congreso Internacional de Arqueología Chilena, Arqueología de Chile central y áreas vecinas. Sociedad Chilena de Arqueología. Viña del Mar: 207-218.

- I964-I969: «Excavaciones en quebrada El Encanto, nuevas evidencias». Actas del v Congreso Nacional de Arqueología Chilena. Museo Arqueológico, La Serena/Sociedad Chilena de Arqueología: 185-206.

- I964-I97I: «Secuencia Arqueológica del alero rocoso de San Pedro Viejo de Pichasca». Boletín del Museo Arqueológico de La Serena I4: 45-69.

ArAdo, M. et alii 2000: "Aportes de la toxicología a la investigación arqueológica y etnobotánica». En Acta Toxicológica argentina. Buenos Aires vil: 45-46.

Artigas, D. 2003: «El Sueño Esculpido: Arte Rupestre y Memoria del Mito en el Valle de Canelillo. Provincia del Choapa». Memoria para optar al título de Arqueólogo. Departamento de Antropología. Universidad de Chile. Santiago.

Aschero, C.A., Martel. A . \& Marcos, S. 2003: «El sitio Curuto 5: nuevos grabados rupestres en Antofagasta de la Sierra (Catamarca, Argentina)». Simposio Internacional de Arte Rupestre SIARB, Tarija (Bolivia): v. Arte Rupestre en Sudamérica. Rupestre Digital GIPRI, Colombia.

Aschero, C. 2007: «Iconos, huancas y complejidad en la Puna sur argentina». Producción y Circulación Prehispánica de Bienes en el Sur Andino. Compilado por A. Nielsen et al., Córdoba. Editorial Brujas: 135-165.

Ballereau, D. \& Niemeyer Fernández, H. i999: «Los sitios rupestres del Valle del Río Hurtado Superior (Norte Chico, Chile)». Chungará, Revista de Antropología Chilena xxI, II: 229-292.

BÁrCENA, R. I974: «Nuevos testimonios de la presencia humana prehistórica en el Noroeste de la provincia de Mendoza». Actualidad Antropológica xv: 5-8.

- I974-I975: «Antropología Física del Valle de Uspallata (provincia de Mendoza)». Anales de Arqueología y Etnología xxıX-Xxx. En prensa.

- I977: «Informe sobre recientes investigaciones arqueológicas en el No de la provincia de Mendoza-Argentina (Valle de Uspallata y zonas vecinas)». Actas del vil Congreso Nacional de Arqueología 11: 66I-692. Talca, Chile.

- 2004: «Nota sobre un nuevo sitio con grabados rupestres en el Departamento San Carlos, Provincia de Mendoza. Reconocimientos arqueológicos en la Estancia Tierras Blancas». Relaciones de la Sociedad Argentina de Antropología. Buenos Aires.

— 20I3: «Grabados del área de la quebrada de la Chilca, vertiente occidental de la sierra de Valle Fértil, Provincia de San Juan, Argentina». Anales de Arqueología y Etnología: 89-I20. 
CABELlO, G. 20II: «De rostros a espacios compositivos: una propuesta estilística para el Valle de Chalinga, Chile». Chungara, Revista de Antropología Chilena Xuılı, I: 25-36.

CAHIzA, P. 2003: «La Dominación Inca en las Tierras Bajas de Mendoza y San Juan». (Tesis doctoral inédita), Facultad de Filosofía y Letras, Universidad Nacional de Cuyo, Mendoza.

- 20I0-20II: «Las piedras marcadas. Representaciones rupestres del piedemonte de la sierra de Valle Fértil, San Juan». Anales de Arqueología y Etnología. Mendoza.

Castelleti, J. 2008: «La serpiente en el arte rupestre de Nocui, norte semiárido de Chile». Estudios Atacameños xxxvi: 73-91.

CASTILLO, G. 1985: «Revisión del arte rupestre Molle». Estudios en arte rupestre: I73-I94.

Criado, F. 2000: «Walking about Lévi-Strauss. Contributions to an Archaeology of Thought». En C. Holtorf \& H. Karlsson (eds.) Philosophy and Archaeological Practice. Göteborg. Bricoleur Press: 277-304.

- I999: «Del terreno al espacio: planteamientos y perspectivas para la Arqueología del Paisaje». TAPA 6.

DebenEDETTI, S. I9I7: «Investigaciones arqueológicas en los valles preandinos de la provincia de San Juan». Publicaciones de la Sección Antropológica I5: I-I84.

Dobres, M. 2000: Technology Social Agency: outlining a practice framework for archaeology. Blackwell Publishers. London.

Fromm, E. I957: «El lenguaje olvidado». Introducción a la Comprensión de los sueños, mitos y cuentos de hadas. Colección Saber, Librería Hachette. Buenos Aires.

GAMBieR, D. I980: «El proceso de agriculturación del sur de Cuyo. La cultura del Atuel II». Actas del v Congreso Nacional de Arqueología Argentina 1: 23I-252.

Gordon, A. I985: «El símbolo de los petroglifos caras sagradas y el culto al agua y de los antepasados en el valle El Encanto». En C. Aldunate, J. Berenguer \& V. Castro (eds.), Estudios en arte rupestre. Museo Chileno de Arte Precolombino. Santiago: 265-278.

GudEMOS, M. 20I2: «Noroeste ¿Una danza de integración regional en las pinturas rupestres de La Salamanca?». Argentina.

HART, L. 2OI2: «Secuencias gráficas. Un recurso común entre el arte prehistórico y el contemporáneo. I Simposio Internacional de Arte Rupestre. Universidad Nacional de Colombia. Bogotá.

IribarReN, J. I949: «Paradero indígena del Estero Las Peñas, Ovalle-Provincia de Coquimbo». Publicaciones del Museo Arqueológico de La Serena, Boletín Iv: I4-I6.

— I953: «Revisión de los petroglifos del valle de río Hurtado». Revista Universitaria xxxv1II: I89-I93.

- I955-56: «Revisión de los petroglifos del valle de río Hurtado III-Sector Las Breas». Revista Universitaria XL-XLI: 53-57.

- I970: «Arqueología y antecedentes históricos del valle del río Hurtado». Museo Arqueológico de La Serena. Chile.

- I975: «Arqueología en la hoya hidrográfica del río Limarí. iv Región Coquimbo». Museo Arqueológico de La Serena. Chile.

LaGigliA, H. I968: «Secuencias culturales del Centro-Oeste Argentino: Valles del Atuel y Diamante». Revista Científica de Investigaciones Museo de Historia Natural de San Rafael I, IV: I59-I74.

- 1974: «Atuel iv ante la prehistoria americana». III Congreso Nacional de Arqueología Argentina. Salta.

LlamaZARES, A.M. I999: «El arte rupestre de la cueva La Candelaria, provincia de Catamarca, Argentina». En Publicaciones del CIFFYH L: I-26. 
- 2000: «Arte chamánico del antiguo noroeste argentino». En Visión Chamánica 111: 44-50.

- 2003: «Arte prehistórico del Noroeste argentino». En Precolombart 5/5, Museo Barbier-Muller d'Art Precolombí. Barcelona.

LEMONNIER, P. 1986: «The study of material culture today: toward an anthropology of technical systems». Journal of Anthropological Archaeology.

- 1992: «Elements for an Anthropology of Technology». Anthropological Paper LxxxviII. Museum of Anthropology, University of Michigan, Ann Arbor.

MARTEL, A.R. 2009: «Pastores, cóndores y ofrendas: la ritualidad pastoril vista desde el arte rupestre del Valle Encantado (departamento San Carlos, Salta)». Museo Arqueológico de Cachi Pío Pablo Díaz Estudios. Antropología Historia: 43-6I.

Mostny, G \& Niemeyer, H. 1983: «Arte rupestre chileno». Ministerio de Educación. Santiago de Chile.

Niemeyer, H \& Montané, J. I968: «El arte rupestre Indígena en la zona centro sur de Chile». Actas y Memoria del xxxvil Congreso Internacional de Americanistas II: 4I9-452.

Niemeyer, H. I968-69: «Los petroglifos de Taltape (Valle de Camarones, Prov. de Tarapacá)». Boletín del Museo Nacional de Historia Natural: 95-II7.

- I969-70: «El yacimiento arqueológico de Huana». Boletín de Prehistoria de Chile II-III: $69-86$.

- I994: «La prehistoria del Valle del río Hurtado (Cuenca de Limarí, Región de Coquimbo)». En Río Hurtado, Historia, Tradición. Rodrigo Ibarren (ed.). Editorial I Municipalidad de Río Hurtado-Museo de Limarí, Dirección de Bibliotecas, Archivos y Museos.

Niemeyer, H. \& CAstillo, G. 1996: «Los yacimientos arqueológicos del estero de San Pedro de Quiles (comuna de Punitaqui, provincia del Limarí)». Boletín del Museo Arqueológico de La Serena XIX: 53-88.

Niemeyer, H. \& BAllereaU, D. 2004: «Arte rupestre del Río Grande, cuenca del Río Limarí, Norte Chico, Chile». Chungará, Revista de Antropología Chilena xxxvi, I: I37-IoI.

NúÑEZ, L. 1967: «Informe arqueológico sobre una muestra de posible narcótico del sitio Patillos-I (Provincia de Tarapacá, Norte de Chile)». Arstryck: 83-90.

Paskoff, R. I970: «Le Chili semi-aride, recherches géomorphologiques». Biscaye.

PAvlovic, D. et alii 2004: «Por cerros, valles y rinconadas: Primeras investigaciones arqueológicas sistemáticas en el Valle de Putaendo, cuenca superior del río Aconcagua». Actas del xv Congreso nacional de Arqueología Chilena 11: 847-860.

Pérez Gollán, J.A. \& Gordillo, E.I. I993: «Alucinógenos y sociedades indígenas del noroeste argentino». En Anales de Antropología Instituto de Investigaciones Antropológicas (UNAM) XXX: 299-345.

QuesadA, M.N. \& GHECO, V. 20Ir: «Modalidades espaciales y formas rituales. Los paisajes rupestres de El Alto-Ancasti». Revista de Arqueología Comechingonia xv: I7-37.

ReCAlDE, M.A. \& PASTOR, S. 20II: «Variabilidad y dispersión de los diseños de camélidos en el occidente de Córdoba (argentina). Circulación de información, reproducción social y construcciones territoriales prehispánicas». Revista de Arqueología Comechingonia xv: 95-II6.

- 20I2: «Contextos públicos y privados para la ejecución del arte rupestre en el valle de Guasapampa (Córdoba, Argentina)». Latin American Antiquity xxı11, 111: 327-345.

Rusconı, C. 1962: «Poblaciones Pre y Post hispánicas de Mendoza». Arqueología 111.

SÁNCHEZ, R. et alii I999: «Informe de Avance». Informe Fondecyt n. ${ }^{\circ}$ I.970.53I.

SCHOBINGER, J. I962: «Representaciones de mascaras en los petroglifos del occidente argentino». Antrophos LVII. 
— I966: «Nota sobre los petroglifos de Talampaya (prov. La Rioja)». Antiquitas: 11.

- I968: «El arte rupestre del occidente argentino (so de La Rioja, San Juan y Mendoza)». Actas del $37 .{ }^{\circ}$ Congreso Internacional de Americanistas 11.

- I971: «Arqueología del valle de Uspallata. Síntesis preliminar». Relaciones: 7I-84.

- 1973: «Prehistoria de Sudamérica». Nueva Colección Labor 95. Barcelona, España.

- I775: «Experiencias psíquicas y cultos esotéricos reflejados en el arte rupestre sudamericano». Valcamónica Symposium, Symposium International sur les Réligions de la Préhistoire: $49 \mathrm{I}-498$.

- I982: «Los petroglifos del Cerro Tunduqueral, Uspallata, Prov. Mendoza, Argentina». Ars Praehistorica I: 123-I39.

- 1997: «Arte Prehistórico de América». Editorial Jaca Book \& Consejo Nacional para la Cultura y las Artes, Coedición México y Milán.

- 2009: "Arqueología y Arte Rupestre de la Región Cuyana». Editorial de la Universidad de Filosofía y Letras, Universidad Nacional de Cuyo. Mendoza, Argentina.

SChobinger, J. \& Gradin, C. 1985: «Arte rupestre de la Argentina». Cazadores de la Patagonia y agricultores andinos. Encuentro Ediciones. Madrid.

Torres, C. 1983: «Tabletas para alucinógenos de San Pedro de Atacama: estilo e iconografía». En Tesoros de San Pedro de Atacama. Museo Chileno de Arte Precolombino. Santiago, Chile.

- I984: «Iconografía de las tabletas para inhalar sustancias psicoactivas de la zona de San Pedro de Atacama, norte de Chile». Estudios Atacameños vil: 178-196.

- I986: «Tabletas para alucinógenos en Sudamérica: tipología, distribución y rutas de difusión». Boletín del Museo Chileno de Arte Precolombino i: 37-53.

Troncoso, A. 2004: «El arte de la dominación: arte rupestre y paisaje durante el período incaico en la cuenca superior del Río Aconcagua», Revista de Antropología Chilena Chungara, Xxxvi, 11: 453-46I.

- I998: «Petroglifos, agua y visibilidad: el arte rupestre y la apropiación del espacio en el curso superior del Río Putaendo, Chile». Revista de Estudios Regionales, Valle Iv: I27-I37.

- 200I: «La Cultura Diaguita en el 200r: Problemas y perspectivas desde el Choapa», Actas del $4 .^{\circ}$ Congreso Chileno de Antropología, Santiago I: I.35I-I.356.

— I998: «Petroglifos, agua y visibilidad: el arte rupestre y la apropiación del espacio en el curso superior del río Puteando». Revista de Estudios Regionales, Valles Iv: I27-I37.

Troncoso, A. et alii 2008: «Arte rupestre en el Valle del Encanto (Ovalle, región de Coquimbo): hacia una revaluación del sitio-tipo del estilo Limarí». Boletín del Museo chileno de arte precolombino. Chile.

Troncoso, A., Criado-Boado, F. \& Santos Estévez, M. 2oir: «Arte rupestre y códigos espaciales. Un caso de estudio en Chile Central». Revista de Antropología Chilena Chungara, XLIII, II: I6I-I76.

Urquiza, S.V. 20II: «Arte rupestre de las Sierras del Norte de Córdoba, Argentina». Arqueología Comechingonia: II5-I37.

Varela, A. \& Riveros, M.G. 2004: «Arte rupestre de San Juan: Petroglifos de Angaco (Obra abierta en el espacio y el tiempo)». Chungará xv1, 11: 663-67I. 
Martí Mas Cornellà \& Mar Zarzalejos Prieto

Editorial / Foreword

\section{Monográfico: Arte rupestre en África, América, Asia y Oceanía}

\section{Agustín Acevedo, Dánae Fiore \& Nora V. Franco}

Imágenes en las rocas: uso del espacio y construcción del paisaje mediante el emplazamiento de arte rupestre en dos regiones de Patagonia centro-meridional (Argentina) / Images on rocks: use of space and landscape construction through the location of rock art in two regions of central-southern Patagonia (Argentina)

55 José Antonio Lasheras Corruchaga \& Pilar Fatás Monforte Itaguy Guasu: un abrigo con grabados de pisadas y abstractos en el Cerro Guasú (Amambay, Paraguay); su contexto en América del Sur / Itaguy Guasu: a rock shelter with footprint and abstract engravings in The Cerro Guasú (Amambay, Paraguay); its context in South America

HUgo ALEXANDER VAN TESLAAR

Interpretación del Arte Rupestre Centro-Sahariano: una aproximación al estilo de Cabezas Redondas / Interpretation of Central Sahara Rock Art: an approach to The Round Head style

\section{GABRIELA InÉs SABATINI \& VANINA VICTORIA TERRAZA}

Distribución del diseño de las cabezas mascariformes en las representaciones rupestres del centro oeste argentino y del norte chico chileno: estilo, identidad y paisaje / Distribution of mask-like forms design in rock art of centre west of Argentina and small north of Chile: style, identity and landscape

14.7 Racso Fernández Ortega, Dany Morales Valdés, Dialvys Rodríguez HernándeZ \& HiLARIO COMEnATE Rodríguez

Las estaciones rupestres de la cordillera de Guaniguanico, Cuba: análisis de evaluación y diagnóstico de los impactos medioambientales / Rock art stations of Guaniguanico mountain range, Cuba: an analysis of the evaluation and diagnosis of environmental impacts

\section{Varia}

173 Ramón Fábregas Valcarce, Carlos Rodríguez Rellán, Jorge GUITIÁN CASTROMIL \& XOÁN GUITIÁN RIVERA

Entre dos mundos: los grabados al aire libre de Pena Bicuda de Loureiro (Teo, Galicia, España) / Between two worlds: prehistoric open-air petroglyphs from Pena Bicuda de Loureiro (Teo, Galicia, Spain)

197 Vicente Castañeda Fernández, IVÁn García Jiménez \& Fernando PRADOS MARTínEZ

Cuestiones sobre la arqueología funeraria en el ámbito del Estrecho de Gibraltar: el ejemplo de la necrópolis de cuevas artificiales de Los Algarbes (Tarifa, Cádiz) / Funerary archaeology issues in the area of the Strait of Gibraltar: the example of artificial cave necropolis of Los Algarbes (Tarifa, Cádiz)
219 ALBERTO PÉREZ VILLA
Una aproximación paleodemográfica comparativa a la estructura de edad y sexo de las poblaciones de la Edad del Bronce en el interior peninsular / A comparative paleodemographic approach to age and sex structure of a Central Iberian Bronze Age populations

\section{ANTONIO PÉREZ LARGACHA}

Tell Brak y Hamoukar: urbanismo en el norte de Mesopotamia en la primera mitad del IV milenio a.C. / Tell Brak and Hamoukar: Urbanism in the north of Mesopotamia in the first half of the $4^{\text {th }}$ millennium b.C.

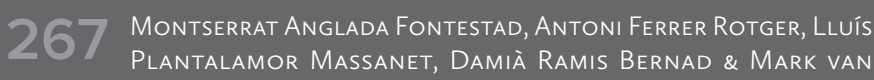
STRYDONCK

La sucesión de ocupaciones entre el Calcolítico y la Edad Media en el yacimiento de Cornia Nou (Menorca, Islas Baleares) / The succession of occupations between the Chalcolithic and Middle Ages in the site of Cornia Nou (Minorca, Balearic Islands)

\section{DOMINGO FERnÁNDEZ MAROTO}

Tornos de alfarero protohistóricos del Cerro de las Cabezas (Valdepeñas, Ciudad Real) / Protohistoric potter's wheels in the Iberian archaeological site 'Cerro de las Cabezas' (Valdepeñas, Ciudad Real)

323 Ángel Morillo Cerdán \& Laura Rodríguez Peinado

Acerca de unos retazos de tejido de lino procedentes del vicus romano de Puente Castro (León, España) / Fragments of linen fabric from the Roman military vicus of Puente Castro (León, Spain)

\subsection{Mónica Major González, Eduardo Penedo Cobo \& Yolanda Peña Cervantes}

El Torcularium del asentamiento rural romano de Los Palacios, Villanueva de Pardillo (Madrid): a propósito de la producción de vino en la zona central de Hispania / The Torcularium at the Roman rural settlement of Los Palacios, Villanueva del Pardillo (Madrid): on the wine production in central Hispania

377 RAúl ARANDA GONZÁlEz

Una aportación al conocimiento de las producciones cerámicas de época visigoda: el conjunto cerámico de la parcela R3 de la Vega Baja (Toledo) / A contribution to the knowledge of the ceramic productions dated of Visigoth period: the ceramic assemblage of R3 plot of Vega Baja (Toledo)

4.47 JaVIer Jiménez GadeA \& Alonso Zamora Canellada Sobre algunas llaves «islámicas» / About some 'Islamic' keys

\section{Recensiones}

483 Flors Ureña, Enric: Los vasos del Palacio de Geldo. Forma, decoración UREÑA)

\section{y simbolismo en la «obra aspra» del siglo XV (ANTONIO MALALANA}

